\title{
Oral findings and its association with prenatal and perinatal factors in newborns
}

Brenda Perez-Aguirre, MSc', Uriel Soto-Barreras, PhD', Juan Pablo Loyola-Rodriguez, PhD², Juan Francisco Reyes-Macias ${ }^{3}$, Miguel Angel Santos-Diaz, MSc ${ }^{3}$, Alejandra Loyola-Leyva, MSc ${ }^{4}$, Obed Garcia-Cortes, MSc ${ }^{3}$

${ }^{1}$ Faculty of Dentistry at Chihuahua University, Chihuahua, ${ }^{2}$ Escuela Superior de Odontología y Doctorado en Ciencias Biomédicas, Universidad Autónoma de Guerrero, Acapulco, ${ }^{3}$ Faculty of Dentistry at San Luis Potosi University, San Luis Potosi, ${ }^{4}$ Doctorado en Ciencias Biomédicas Básicas, San Luis Potosi University, San Luis Potosi, México

Purpose: This study aimed to determine the frequency of abnormalities in the newborn oral cavity and to evaluate the association with prenatal and perinatal factors.

Methods: This cross-sectional study evaluated 2,216 newborns. Oral findings were assessed in the first 24 hours of life using visual examination. Sex, weight, length, gestational age, and medical disorders at birth were recorded. Maternal demographic and medical information was also obtained.

Results: The most common oral findings were Bohn's nodules, Epstein's pearls, and dental lamina cysts. Other intraoral findings included odontogenic cysts, ankyloglossia, and natal teeth, among others. In logistic regression analyses, folic acid consumption during pregnancy was significantly associated with Bohn's nodules (odds ratio [OR], 1.79; 95\% confidence interval [Cl], 1.23-2.55; $P=0.002$ ), Epstein's pearls (OR, 1.63; 95\% Cl, 1.14-2.33; $P=0.007)$, and dental lamina cysts (OR, 1.45; 95\% Cl, 1.02-2.05; $P=0.038$ ). Moreover, preterm births were negatively associated with prevalence of Bohn's nodules ( $O R$, $0.63 ; 95 \% \mathrm{Cl}, 0.50-0.80 ; P \leq 0.0001)$. Comparison between newborns with and without oral inclusion cysts showed that maternal folic acid and iron intake were significantly different $(P<0.05)$.

Conclusion: Maternal folic acid and iron intake were associated with the prevalence of oral inclusion cysts.

Key words: Infant, Newborn, Mouth abnormalities, Gingival pathology

\section{Introduction}

Abnormalities in the oral cavity of infants are not uncommon, but most are innocuous and resolve with age in the absence of treatment. Some of the most prevalent oral findings are oral inclusion cysts, ${ }^{1)}$ ankyloglossia, ${ }^{2)}$ vascular lesions, ${ }^{3)}$ and natal teeth. ${ }^{4)}$ Other relevant conditions although less frequent are cleft lip and cleft palate, and usually a surgical treatment is needed in the first months of life.

Oral inclusion cysts are described as white, raised, multiple nodules of maxillary and mandibular alveolar ridges and midpalate region. ${ }^{6}$ Fromm classified oral inclusion cysts depending on their location as Epstein pearls (midline raphe or near the junction of the hard and soft palate), Bohn's nodules (buccal and lingual areas of the dental ridges), and dental lamina cysts (located over the alveolar ridge). ${ }^{7)}$ Most inclusion cysts of the alveolar crest and the midpalate region are apparently discharged shortly after birth. Several reports have stated a transient nature of cysts by discharge of keratin at the time of fusion of cyst walls with the oral epithelium. $^{8,9}$

Although oral inclusion cysts in newborns have been widely described, ${ }^{1,6-9)}$ there are few studies evaluating possible associated factors. A previous study found that the occurrence
Corresponding author: Juan Pablo Loyola-Rodríguez, DDS, PhD

Escuela Superior de Odontología, Universidad Autónoma de Guerrero, Av. Ruiz Cortines s/n, Col Infonavit Alta Progreso, CP 39610, Acapulco, Guerrero, México

Tel: +52-664-9797505 (ext. 50237)

Fax: +52-444-1650898

E-mail: juanpablo.loyola8@gmail.com https://orcid.org/0000-0003-0892-0082

Received: 18 October, 2017

Revised: 14 February, 2018

Accepted: 12 March, 2018

Copyright $(\bigodot 2018$ by The Korean Pediatric Society

This is an open-access article distributed under the terms of the Creative Commons Attribution NonCommercial License (http://creativecommons.org/ licenses/by-nc/4.0// which permits unrestricted noncommercial use, distribution, and reproduction in any medium, provided the original work is properly cited. 
of midpalatal and alveolar cysts differed with respect to race, ${ }^{10)}$ being significantly more prevalent in white newborns compared to black newborns. On the other hand, it has been reported a direct relationship between the prevalence of palatal and alveolar cysts with increasing gestational age, increasing postnatal age, and increasing birth weight. ${ }^{11)}$ However, a recent study concluded that the frequency of palatal and gingival cysts was not significantly affected by sex, birth weight, gestational age, or delivery-pattern variables. ${ }^{12)}$ Therefore, the aim of the study was to describe the frequency of abnormalities in the newborn's oral cavity and assess its association with prenatal and perinatal factors.

\section{Materials and methods}

\section{Study population}

This study included newborns within a 6-month period (December 2011 to May 2012) from the Hospital Central Ignacio Morones Prieto and the Hospital El Niño y la Mujer, both located in San Luis Potosi City (northern-central state of Mexico). The ethics committee of both hospitals and the clinical research committee of the Master's Degree in Advanced Education in General Dentistry at San Luis Potosi University approved the study. Informed parents or legal caregivers signed a written informed consent. Newborns that were breathing and had a stable health condition were included in the study. Newborns requiring intensive care were excluded.

\section{Clinical examination and medical information}

An expert in oral pathology calibrated the examiner in all variables through intraclass correlation coefficient for the reliability of the measurements. Oral findings were observed in the first 24 hours of life by visual examination. The assessment was performed using gloves, a spatula tongue depressor, and with a head flashlight. The variables examined in the oral mucosa were: location of the maxillary labial midline frenum, the symmetry of the alveolar ridges, and the presence of developmental oral inclusion cyst. Also, the presence of Fordyce's spots/granules, ankyloglossia, and natal teeth were noted. Additional information including baby's sex, birthweight, length, gestational age at delivery, Apgar scores, parity, medical disorders at birth and mode of delivery was also considered.

All the mothers were evaluated by an obstetrician during and after pregnancy, who obtained information about various maternal traits (including age, history of systemic diseases, complications during pregnancy, supplements prescribed during pregnancy, alcohol consumption, and smoking) were collected on the medical record of each patient. All women were asked about the types of vitamin supplements they used (prenatal vitamins, folic acid, iron, calcium, and other types). However, information on dosage of folic acid and multivitamin supplements was not available for all cases.

\section{Statistical analysis}

Quantitative data are expressed as a mean and standard deviation. Qualitative data are expressed as frequency and proportion. The odds ratio (OR) with 95\% confidence interval (CI) were calculated using a logistic regression model to estimate the associations between Bohn's nodules, Epstein's pearls and dental lamina cysts (dependent variables) with the exposure to supplements prescribed during pregnancy (independent variables). Estimates were adjusted for mother's age, preeclampsia, urinary tract infection, gestational age and newborn's sex and weight in the analysis. For the adjustment, models were verified with Hosmer-Lemeshow tests. Data were analyzed using the IBM SPSS Statistics ver. 23.0 (IBM Co., Armonk, NY, USA). Statistical significance was set at $\alpha=0.05$.

\section{Results}

A total of 2,216 newborns were evaluated in the 2 hospitals. The distribution based on sex was similar, with a slightly larger number of males (53.16\%). The most common oral findings were Bohn's nodules, Epstein's pearls, and dental lamina cysts (Fig. 1). Additionally, in some cases, other intraoral findings were also observed such as odontogenic cysts, ankyloglossia, natal teeth, and vascular malformations (Table 1).

A total of 9,542 Bohn's nodules and 2,320 dental lamina cyst were observed in the examined neonates (Table 2). Bohn's nodules were more frequently located in the anterior buccal area and the posterior buccal areas of the maxilla. Similarly, dental lamina cysts were more frequent in the maxilla, with most cysts present posteriorly. Moreover, 4,520 Epstein pearls were recorded in 66\% of neonates, all occurring along the midline of the hard palate. Table 3 shows relevant data of the pregnant women. About fifty percent

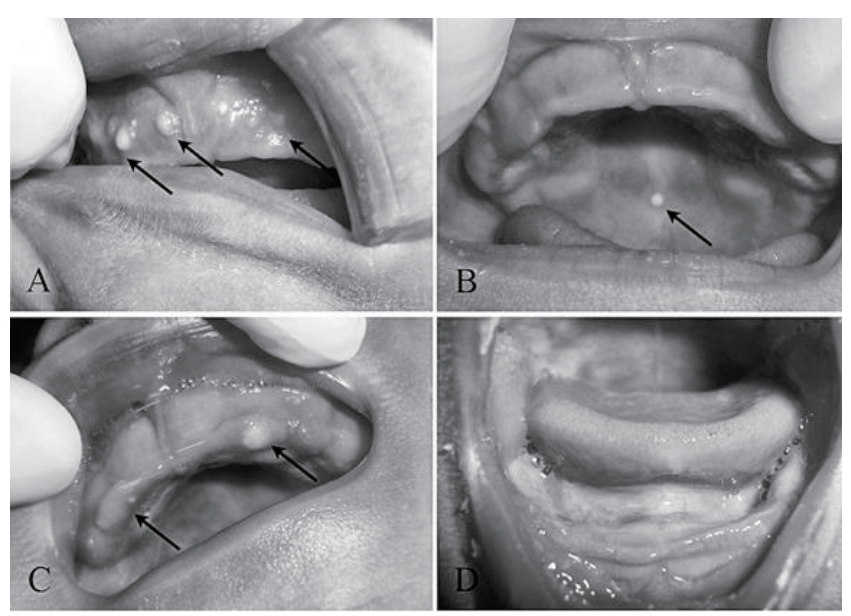

Fig. 1. Representative image of oral inclusion cysts (arrows). (A) Bohn's nodules. (B) Epstein's pearls. (C) Dental lamina cysts. (D) Normal oral mucosa. 
Table 1. Prevalence of oral findings and genetic disorders in newborns

\begin{tabular}{lccc}
\hline Variable & $\begin{array}{c}\text { Female } \\
(\mathrm{n}=1,038)\end{array}$ & $\begin{array}{c}\text { Male } \\
(\mathrm{n}=1,178)\end{array}$ & $\begin{array}{c}\text { Total } \\
(\mathrm{n}=2,216)\end{array}$ \\
\hline Bohn's nodules & $718(69.2)$ & $832(70.6)$ & $1,550(70.0)$ \\
Epstein's pearls & $676(65.1)$ & $787(66.8)$ & $1,463(66.0)$ \\
Dental lamina cysts & $461(44.4)$ & $530(45.0)$ & $991(44.7)$ \\
Odontogenic cysts & $32(3.1)$ & $24(2.03)$ & $56(2.5)$ \\
Ankyloglossia & $16(1.5)$ & $17(1.4)$ & $33(1.5)$ \\
Natal teeth & $4(0.4)$ & $5(0.4)$ & $9(0.4)$ \\
Vascular malformation & $2(0.2)$ & $4(0.3)$ & $6(0.3)$ \\
Congenital melanocytic nevi & $1(0.1)$ & $0(0)$ & $1(0.1)$ \\
Lipoma & $1(0.1)$ & $2(0.2)$ & $3(0.1)$ \\
Cleft lip & $1(0.1)$ & $0(0)$ & $1(0.1)$ \\
Cleft palate & $1(0.1)$ & $0(0)$ & $1(0.1)$
\end{tabular}

Values are presented as number (\%).

Table 2. Distribution of Bohn's nodules and dental lamina cysts by location and sex

\begin{tabular}{lccr}
\hline Variable & Female & Male & Total \\
\hline Bohn's nodules $(\mathrm{n}=9,542)$ & & & \\
$\quad$ Buccal anterior & $1,530(43.5)$ & $2,092(45.9)$ & $3,622(44.8)$ \\
Buccal posterior & $1,920(54.6)$ & $2,316(50.8)$ & $4,236(52.4)$ \\
Palatal anterior & $66(1.9)$ & $147(3.2)$ & $213(2.6)$ \\
Palatal posterior & $0(0)$ & $7(0.2)$ & $7(0.1)$ \\
Total & $3,516(100)$ & $4,562(100)$ & $8,078(100)$ \\
Mandible & & & \\
Buccal anterior & $131(20.4)$ & $90(10.9)$ & $180(12.3)$ \\
Buccal posterior & $318(49.6)$ & $416(50.5)$ & $734(50.1)$ \\
Lingual anterior & $90(14.0)$ & $174(21.1)$ & $305(20.8)$ \\
Lingual posterior & $102(15.9)$ & $143(17.4)$ & $245(16.8)$ \\
Total & $641(100)$ & $823(100)$ & $1,464(100)$ \\
Dental lamina cysts $(\mathrm{n}=2,320)$ & & & \\
Maxilla & & & \\
Anterior & $134(15.2)$ & $177(14.3)$ & $311(14.7)$ \\
Posterior & $750(84.8)$ & $1,061(85.7)$ & $1,811(85.3)$ \\
Total & $884(100)$ & $1,238(100)$ & $2,122(100)$ \\
Mandible & & & \\
Anterior & $74(80.4)$ & $93(87.7)$ & $167(84.3)$ \\
Posterior & $18(19.6)$ & $13(12.3)$ & $31(15.7)$ \\
Total & $92(100)$ & $106(100)$ & $198(100)$ \\
\hline
\end{tabular}

Values are presented as number (\%).

of the mothers were between 20 to 29 years old. History of systemic diseases in pregnant women was unusual; the prevalence of hypertension and diabetes mellitus was recorded about one percent. The most prevalent complications during pregnancy were infectious (bacterial urinary tract and yeast infections). The majority of women reported intake of supplements during their pregnancy, including folic acid, iron, and calcium. Alcohol and tobacco use during preg-
Table 3. Maternal prenatal medical data $(n=2,168)$

\begin{tabular}{lc}
\hline Variable & Number (\%) \\
\hline Age (yr) & $631(29.1)$ \\
$14-19$ & $1,093(50.4)$ \\
$20-29$ & $405(18.7)$ \\
$30-39$ & $39(1.8)$ \\
$>40$ & \\
Systemic disease & $22(1.01)$ \\
Diabetes mellitus & $27(1.3)$ \\
Hypertension & $7(0.3)$ \\
Hypothyroidism & $6(0.3)$ \\
Epilepsy & $5(0.2)$ \\
Asthma & \\
Disease occurred during pregnancy & $1,045(48.2)$ \\
Urinary tract infection & $102(4.7)$ \\
Yeast infection & $49(2.3)$ \\
Preeclampsia & $26(1.2)$ \\
Gestational diabetes mellitus & \\
Supplements prescribed during pregnancy. & $1,629(75.1)$ \\
Folic acid & $1,478(68.2)$ \\
Iron & $55(2.5)$ \\
Calcium &
\end{tabular}

nancy was reported 1.6\% and 9.9\%, respectively.

In the logistic regression analyses, folic acid consumption during pregnancy raised significantly for Bohn's nodules (OR, 1.79; 95\% CI, $1.23-2.55 ; P=0.002)$, Epstein pearls (OR, 1.63; 95\% CI, 1.14-2.33; $P=0.007$ ), and dental lamina cysts (OR, $1.45 ; 95 \% \mathrm{CI}, 1.02-2.05$; $P=0.038)$. On the other hand, preterm births were less likely to experience Bohn`s nodules (OR, 0.63; 95\% CI, 0.5-0.8; $P=0.007$ ). No significant associations were found in the use of the others traits such as calcium and iron intake, mother's age, preeclampsia, urinary tract infection, newborn's sex, and low birth weight (Table 4). Table 5 shows comparisons of basic traits of newborns with or without oral inclusion cysts; there is a statistically significant difference $(<0.05)$ in folic acid and iron intake between groups.

\section{Discussion}

In this study, $91.2 \%$ of neonates showed some anomalies in the oral cavity, being the most common finding the inclusion cystic lesions. These results are consistent with previous evidence that have shown high prevalence of oral cysts in newborns, ranging between 29\% and 99\%. ${ }^{3,13,14)}$ While most of the studies have found a higher frequency of palatal cysts compared to gingival cysts, ${ }^{9,10,14)}$ our study presented contradictory results, with $66 \%$ of palatal cysts and 79\% of gingival cysts of the population examined. The reason of this variation is not clear, but difference in race/ethnicity, 
Table 4. Adjusted OR and 95\% Cl for the association between oral inclusion cysts in newborns and supplements prescribed during pregnancy

\begin{tabular}{|c|c|c|c|c|c|c|}
\hline \multirow{2}{*}{ Variable } & \multicolumn{2}{|c|}{ Bohn's nodules } & \multicolumn{2}{|c|}{ Epstein's pearls } & \multicolumn{2}{|l|}{ Dental lamina cysts } \\
\hline & OR (95 \% Cl) & $P$ value & OR (95 \% Cl) & $P$ value & OR $(95 \%$ Cl) & $P$ value \\
\hline Folic acid use & $1.79(1.23-2.55)$ & $0.002^{*}$ & $1.63(1.14-2.33)$ & $0.007^{*}$ & $1.45(1.02-2.05)$ & $0.038^{*}$ \\
\hline Calcium use & $1.31(0.72-2.37)$ & 0.381 & $0.83(0.49-1.41)$ & 0.501 & $0.85(0.51-1.43)$ & 0.553 \\
\hline Iron use & $1.05(0.75-1.47)$ & 0.799 & $1.04(0.76-1.44)$ & 0.794 & $0.92(0.67-1.25)$ & 0.582 \\
\hline Mother's age <20 yr & $0.90(0.72-1.11)$ & 0.317 & $0.98(0.80-1.20)$ & 0.878 & $1.02(0.84-1.25)$ & 0.815 \\
\hline Mother's age $\geq 40 \mathrm{yr}$ & $0.79(0.43-1.45)$ & 0.434 & $1.02(0.56-1.89)$ & 0.926 & $0.48(0.24-0.93)$ & 0.129 \\
\hline Preeclampsia & $0.86(0.50-1.46)$ & 0.561 & $0.69(0.40-1.16)$ & 0.158 & $0.71(0.41-1.22)$ & 0.216 \\
\hline Urinary tract infection & $0.51(0.20-1.29)$ & 0.153 & $1.57(0.55-4.44)$ & 0.397 & $0.88(0.68-1.17)$ & 0.245 \\
\hline Newborn's male sex & $1.19(0.99-1.42)$ & 0.063 & $1.22(1.03-1.46)$ & 0.055 & $1.12(0.95-1.33)$ & 0.188 \\
\hline Preterm birth ${ }^{\dagger}$ & $0.63(0.50-0.80)$ & $<0.0001^{*}$ & $1.06(0.83-1.35)$ & 0.658 & $0.86(0.68-1.10)$ & 0.225 \\
\hline Posterm birth ${ }^{\ddagger}$ & $0.63(0.10-3.80)$ & 0.609 & $2.35(0.26-8.3)$ & 0.448 & $1.87(0.31-11.2)$ & 0.498 \\
\hline Low birth weight ${ }^{\S}$ & $0.97(0.79-1.36)$ & 0.857 & $1.38(0.94-1.88)$ & 0.129 & $0.82(0.59-1.14)$ & 0.238 \\
\hline
\end{tabular}

$\mathrm{OR}$, odds ratio; $\mathrm{Cl}$, confidence interval.

${ }^{\star} P<0.05$, statistically significant. ${ }^{\dagger}<37$ weeks of pregnancy. ${ }^{\ddagger} 42$ Weeks of pregnancy. ${ }^{\S}$ Birth weight less than $2,500 \mathrm{~g}$.

Table 5. Comparison of traits in newborns with and without oral inclusion cysts (OICs)

\begin{tabular}{|c|c|c|c|c|c|}
\hline \multirow{2}{*}{ Variable } & \multicolumn{2}{|c|}{ Presence of OIC $(n=2,021)$} & \multicolumn{2}{|c|}{ No presence of OIC $(n=195)$} & \multirow{2}{*}{$P$ value } \\
\hline & №. $(\%)$ & Mean \pm SD & №. $(\%)$ & Mean \pm SD & \\
\hline Male newborns & $1,077(53.3)$ & - & $101(51.8)$ & - & 0.806 \\
\hline Female newborns & $944(46.7)$ & - & $94(48.2)$ & - & \\
\hline Folic acid & $1,524(75.4)$ & - & $105(53.8)$ & - & $<0.001$ \\
\hline Iron & $1,369(67.7)$ & - & $109(55.9)$ & - & $<0.001$ \\
\hline Calcium & $52(2.57)$ & - & $3(1.54)$ & - & 0.368 \\
\hline Mother's age (yr) & - & $24.2 \pm 6.44$ & - & $24.5 \pm 6.54$ & 0.574 \\
\hline Gestational age (yr) & - & $38.9 \pm 0.150$ & - & $38.6 \pm 0.125$ & 0.518 \\
\hline Birth weight (g) & - & $3099.9 \pm 455$ & - & $3,072 \pm 473$ & 0.639 \\
\hline Birth length (cm) & - & $49.8 \pm 2.29$ & - & $50.1 \pm 2.03$ & 0.273 \\
\hline
\end{tabular}

SD, standard deviation.

${ }^{*}$ Chi-square test for qualitative variables and Mann Whitney $U$ test for quantitative variables.

sample size and methodology could be related. Several studies have shown an oral cysts racial predilection, concluding that oral cysts occur more likely in newborn of Caucasian origin compared to African-American newborns. ${ }^{10,15)}$ All neonates included in our study consisted in Mexican mestizo race located in the north central region of the country. Thus, we were unable to make a comparison between race/ethnicity.

While previous studies have shown prevalence of ankyloglossia between $2.5 \%$ and $10.6 \%{ }^{3,10,14)}$ with predilection in males, ${ }^{10)}$ our results indicated an occurrence of $1.5 \%$ equally distributed in both male and female newborns. In agreement with similar studies around one percent or less of the population presented natal teeth, ${ }^{4,16)}$ and congenital melanocytic nevi. ${ }^{3)}$

After adjusted logistic regression multivariate analysis models, this study showed a positive association between inclusion cysts (Bohn nodules, Epstein pearls, and dental lamina cysts) and prescribed folic acid intake during pregnancy. This relationship could be limited to several factors. For instance, although all women selfreported the types of vitamins and supplements prescribed and used during pregnancy, we could not assure women adherence during periconceptional period due to the cross-sectional design of our study. Adverse effects of folic acid supplementation during pregnancy in offspring have been described, such as insulin resistance and greater adiposity, ${ }^{17)}$ childhood obesity and type 2 diabetes mellitus, ${ }^{18)}$ asthma ${ }^{19)}$ and worse memory scores. ${ }^{20)}$ To the best of our knowledge, no study has investigated the association between supplemented folic acid intake and oral inclusion cysts or other oral alterations in newborns.

Oral inclusion cysts have been histologically described as microkeratocysts derived from epithelial remnants of the palatal shelves and dental lamina. Epstein pearls are derived from epithelial remnants after fusion of the palatal shelves and Bohn's nodules and dental lamina cysts are remnants of degenerating dental lamina. ${ }^{1,8,21)}$ These epithelial remnants could proliferate, keratinize, and form 
small cysts. ${ }^{11)}$ Although the association of oral inclusion cysts and folic acid suggested in this study has not been previously described, a plausible biological explanation could be related to the fact that many cells can and do modify their phenotypes in response to factors that affect folate metabolism. ${ }^{22,23)}$ Furthermore, several studies have demonstrated the importance of folic acid (alone o combined with other drugs) in the stimulation of cell growth, metabolic activity, and cell survival. ${ }^{23-25)}$ Also, changes in gingival cells have also been observed by the effect of folic acid, reducing cell-associated inflammatory response in human gingival fibroblasts stimulated with phenytoin and tumor necrosis factor- $\alpha^{26)}$ Furthermore, folic acid is used combined with D-Chiro-Inositol to improve ovarian function and fertility in women affected by polycystic ovary syndrome. ${ }^{27)}$ Additionally, a significant difference was found between iron use during pregnancy with the presence of oral inclusion cysts. Evidence exists that prenatal iron intake improves birth weight ${ }^{28)}$ gestational age ${ }^{29)}$ and child intellectual development. ${ }^{30)}$ But, there have been no reports of iron use in pregnancy with oral findings in newborns.

An earlier report established a statistically significant less prevalence of palatal and alveolar cysts in premature neonates compared to full-term neonates, assuming a positive association of increased gestational age, increased postnatal age, and increased birth weight with the prevalence of cysts. ${ }^{11)}$ In our study, preterm births were negatively associated with Bohn's nodules, but no associations were found for Epstein pearls and gingiva lamina cysts. It is important to notice that all newborns were evaluated in their first 24 hours of life, unlike the oral examinations performed by Donley and Nelson, ${ }^{11)}$ where the exams occurred on an average of 12 days after birth. The later evaluation could represent a possible disadvantage, because it has been demonstrated that most of the oral inclusion cysts seem to disappear within a few weeks after birth. ${ }^{7,14-16,31)}$ Moreover, it has been proposed a significant relationship between gestational diabetes, insulin treatment and cigarette consumption with the presence of oral inclusion cysts. ${ }^{10)}$ In our study, no associations between oral anomalies and maternal characteristics like age, systemic diseases, and habits (smoking, alcohol) were observed.

In conclusion, with the limitations of this study, our results suggest that folic acid could be related with the prevalence of Bohn's nodules, Epstein pearls, and dental lamina cysts in newborns. While high folic acid intake is a concern and the health implications are unclear, these anomalies do not represent a pathological concern because of its innocuous and self-limiting nature. However, further longitudinal studies are needed to explain this association.

\section{Conflicts of interest}

No potential conflict of interest relevant to this article was reported.

\section{Acknowledgments}

This research was supported by CONACYT (grant number: 157329 and 254422) and PIFI2014-UASLP.

\section{References}

1. Cataldo E, Berkman MD. Cysts of the oral mucosa in newborns. Am J Dis Child 1968;116:44-8.

2. Ballard JL, Auer CE, Khoury JC. Ankyloglossia: assessment, incidence, and effect of frenuloplasty on the breastfeeding dyad. Pediatrics 2002;110:e63.

3. Freudenberger S, Santos Díaz MA, Bravo JM, Sedano HO. Intraoral findings and other developmental conditions in Mexican neonates. J Dent Child (Chic) 2008;75:280-6.

4. Leung AK, Robson WL. Natal teeth: a review. J Natl Med Assoc 2006; 98:226-8.

5. Robin NH, Baty H, Franklin J, Guyton FC, Mann J, Woolley AL, et al. The multidisciplinary evaluation and management of cleft lip and palate. South Med J 2006;99:1111-20.

6. Hooley JR. The infant's mouth. J Am Dent Assoc 1967;75:95-103.

7. Fromm A. Epstein's pearls, Bohn's nodules and inclusion-cysts of the oral cavity. J Dent Child 1967;34:275-87.

8. Moreillon MC, Schroeder HE. Numerical frequency of epithelial abnormalities, particularly microkeratocysts, in the developing human oral mucosa. Oral Surg Oral Med Oral Pathol 1982;53:44-55.

9. Paula JD, Dezan CC, Frossard WT, Walter LR, Pinto LM. Oral and facial inclusion cysts in newborns. J Clin Pediatr Dent 2006;31:127-9.

10. Friend GW, Harris EF, Mincer HH, Fong TL, Carruth KR. Oral anomalies in the neonate, by race and gender, in an urban setting. Pediatr Dent 1990;12:157-61.

11. Donley CL, Nelson LP. Comparison of palatal and alveolar cysts of the newborn in premature and full-term infants. Pediatr Dent 2000;22: 321-4.

12. Liu MH, Huang WH. Oral abnormalities in Taiwanese newborns. J Dent Child (Chic) 2004;71:118-20.

13. Cetinkaya M, Oz FT, Orhan AI, Orhan K, Karabulut B, Can-Karabulut DC,et al. Prevalence of oral abnormalities in a Turkish newborn population. Int Dent J 2011;61:90-100.

14. Flinck A, Paludan A, Matsson L, Holm AK, Axelsson I. Oral findings in a group of newborn Swedish children. Int J Paediatr Dent 1994; 4:67-73.

15. Jorgenson RJ, Shapiro SD, Salinas CF, Levin LS. Intraoral findings and anomalies in neonates. Pediatrics 1982;69:577-82.

16. George D, Bhat SS, Hegde SK. Oral findings in newborn children in and around Mangalore, Karnataka State, India. Med Princ Pract 2008;17:385-9.

17. Krishnaveni GV, Veena SR, Karat SC, Yajnik CS, Fall CH. Association between maternal folate concentrations during pregnancy and insulin resistance in Indian children. Diabetologia 2014;57:110-21.

18. Popkin BM, Doak CM. The obesity epidemic is a worldwide phenomenon. Nutr Rev 1998;56(4 Pt 1):106-14.

19. Whitrow MJ, Moore VM, Rumbold AR, Davies MJ. Effect of supplemental folic acid in pregnancy on childhood asthma: a prospective 
birth cohort study. Am J Epidemiol 2009;170:1486-93.

20. Philip D, Buch A, Moorthy D, Scott TM, Parnell LD, Lai CQ, et al. Dihydrofolate reductase 19-bp deletion polymorphism modifies the association of folate status with memory in a cross-sectional multiethnic study of adults. Am J Clin Nutr 2015;102:1279-88.

21. Burke GW Jr, Feagans WM, Elzay RP, Schwartz LD. Some aspects of the origin and fate of midpalatal cysts in human fetuses. J Dent Res 1966;45:159-64.

22. Price RJ, Lillycrop KA, Burdge GC. Folic acid induces cell type-specific changes in the transcriptome of breast cancer cell lines: a proof-ofconcept study. J Nutr Sci 2016;5:e17.

23. McCabe J, Chang S, Hajibandeh J, Tran MD, Meeder CA, Sharma K, et al. Folate supplementation induces differential dose-dependent modulation of proliferative phenotypes among cancerous and noncancerous oral cell lines in vitro. J Diet Suppl 2010;7:325-40.

24. Pellis L, Dommels Y, Venema D, Polanen Av, Lips E, Baykus H, et al. High folic acid increases cell turnover and lowers differentiation and iron content in human HT29 colon cancer cells. Br J Nutr 2008;99: 703-8.

25. Yu M, Li W, Luo S, Zhang Y, Liu H, Gao Y, et al. Folic acid stimulation of neural stem cell proliferation is associated with altered methylation profile of PI3K/Akt/CREB. J Nutr Biochem 2014;25:496-502.

26. Doğan A, Tunca Y, Ozdemir A, Sengül A, Imirzalioğlu N. The effects of folic acid application on IL-1beta levels of human gingival fibroblasts stimulated by phenytoin and TNFalpha in vitro: a preliminary study. J Oral Sci 2001;43:255-60.

27. Laganà AS, Barbaro L, Pizzo A. Evaluation of ovarian function and metabolic factors in women affected by polycystic ovary syndrome after treatment with D-Chiro-Inositol. Arch Gynecol Obstet 2015; 291:1181-6.

28. Haider BA, Olofin I, Wang M, Spiegelman D, Ezzati M, Fawzi WW, et al. Anaemia, prenatal iron use, and risk of adverse pregnancy outcomes: systematic review and meta-analysis. BMJ 2013;346:f3443.

29. Zeng L, Dibley MJ, Cheng Y, Dang S, Chang S, Kong L, et al. Impact of micronutrient supplementation during pregnancy on birth weight, duration of gestation, and perinatal mortality in rural western China: double blind cluster randomised controlled trial. BMJ 2008;337: a2001.

30. Christian P, Murray-Kolb LE, Khatry SK, Katz J, Schaefer BA, Cole PM, et al. Prenatal micronutrient supplementation and intellectual and motor function in early school-aged children in Nepal. JAMA 2010;304:2716-23.

31. Cizmeci MN, Kanburoglu MK, Kara S, Tatli MM. Bohn's nodules: peculiar neonatal intraoral lesions mistaken for natal teeth. Eur J Pediatr 2014;173:403. 